\title{
A comida em comunidades quilombolas: reflexões sobre saberes e mercados solidários
}

The food in quilombo communities: reflections on solidarity and knowledge markets

Rafaela Paula Silva

Universidade do Estado do Rio de Janeiro - UERJ - Rio de Janeiro - Rio de Janeiro - Brasil

\section{Silvia Regina Baptista}

Fundação Oswaldo Cruz - FIOCRUZ - Rio de Janeiro - Rio de Janeiro - Brasil

Resumo: Este artigo trata da comida nas comunidades remanescentes de quilombo do Maciço da Pedra Branca (RJ) e suas relações em redes de contato e mercados próximos. A metodologia aplicada foi a observação participante entre 2014 e 2016, em duas feiras agroecológicas em que participam seus membros e quatro festividades realizadas. Nestes casos, a comida é vista como elemento central nas trocas sociais, econômicas e culturais. O valor econômico deixa de ser o cerne do processo, substituído por relações de equivalência cultural, significados, símbolos. A comida evidencia um sistema que compreende cultivo, preparo, consumo, troca e comércio de excedentes. Propicia-se assim a formação de nichos de economia solidária, em que o alimento é produzido, preparado e significado com base em referenciais de solidariedade, respeito a natureza, tradicionalidade.

Palavras-chave: Comida. Saberes. Economia da reciprocidade.

Abstract: This article deals with the food in remaining quilombo communities (RJ) of Pedra Branca Massif (RJ) and their relationships in networking and nearby markets. The methodology applied was the participant observation between 2014 and 2016 in two agroecological fairs involving their members and four festivities held. In these cases, the food is seen as a central element in the social, economic and cultural exchanges. The economic value ceases to be the heart of the process, replaced by relations of cultural equivalence, meanings, symbols. The food shows a system that comprising cultivation, preparation, consumption, exchange and trade. It favours, in this way, the formation of solidary economy niches, in which food is produced, prepared and meaning based in reference to solidarity, respect nature, traditionalism.

Keywords: Food. Knowledge. Reciprocity economy. 


\section{Introdução}

Em princípio o ato de comer é inerente à vida dos seres humanos, todos comem para viver, ao mesmo tempo é uma ação individual, pois o que uma pessoa come, não pode ser consumido por outra depois. Todos comem, isso permite que este aspecto fisiológico propicie vivências e situações partilhadas, por exemplo, refeições. Nestas ocasiões indivíduos diferentes se unem para compartilhar uma materialidade comum: 0 alimento.

Consomem uma parte do todo e se aproximam. Por isso, as refeições foram vistas ao longo do tempo, como ocasiões importantes, em que além do alimento, os envolvidos dividiam ideias, origens comuns, costumes. A "comensalidade", ou o comer coletivamente exige alguma regularidade, para que os envolvidos possam se reunir, em detrimento da alimentação como uma resposta mecânica a fome, que pode ocorrer a qualquer momento. Além disso, uma série de regras foram se constituindo para ordenar as refeições com base em referenciais socioculturais. (SIMMEL, 2004, p. 160-162)

O alimento e a maneira como é consumido dizem muito a respeito daquele que come, os humanos são onívoros, ou seja, "podem comer tudo que não os come primeiro". Mas não o fazem necessariamente, criam regras sobre aquilo que pode ou não ser consumido, quando e como. Entre os alimentos potenciais, existem critérios culturais para determinar aquilo que é "comida", essa definição não responde necessariamente a critérios nutritivos ou de segurança alimentar. Além de, decidir pelo consumo deste ou daquele alimento, os seres humanos os inserem numa cadeia hierárquica caracterizando alimentos fortes, fracos, saborosos, nojentos, requintados. (MACIEL, 2001, p.147-149)

Todos estes fatores que envolvem a comida formam sistemas alimentares, também chamados de "cozinhas". A análise de um conjunto de alimentos que possuem relação com as representações do imaginário coletivo, práticas sociais e culturais. Esta é uma interpretação que compreende o fenômeno como múltiplo e multifacetado: a transformação do alimento em comida. Passa da universalidade da definição de cozinha, para a imensa diversidade das cozinhas existentes em diferentes grupos e sociedades, com símbolos e imaginários próprios que Ihes conferem sentido. (MACIEL, 2001, p. 150-151)

Desta maneira, as imagens e o imaginário social perpassados por seus significados simbólicos, formam um sentido, que embora por vezes lide com imagens/alimentos comuns a diversos locais, ou pelo menos com usos que parecem pertencer à universalidade como a noção de cozido ou o próprio ato de alimentar-se, se resignificam com base em suas especificidades históricas e socioculturais. Mesmo partindo de estruturas do inconsciente permitem múltiplas possibilidades de interpretação e significação:

Segundo a perspectiva neoplatônica, as imagens e o imaginário são sinônimos do simbólico, pois as imagens são formas que contêm sentidos afetivos universais ou arquetípicos, cujas explicações remetem a estruturas do inconsciente (Jung, Campbell), ou mesmo às estruturas biopsíquicas e sociais da espécie humana (Durand). Embora considerem que o nível consciente emerge do inconsciente, as especificidades históricas e socioculturais estão relegadas a um segundo plano da análise. Em consequência, as imagens e a sua dinâmica, o imaginário, são identificadas aos símbolos. Os símbolos dão o que falar, escreve Paul Ricoeur, à medida que neles existem os mesmos sentidos que os homens irão redescobrir. Sendo 0 inconsciente depositário dos significados, cabe aos homens a descoberta de sua revelação através das formas em que essas imagens se expressam e se manifestam. (LAPLANTINE; TRINDADE, 1996, p.5)

Há tempos a Antropologia considera estas escolhas alimentares como derivadas da cultura. Os alimentos, conforme apontam Canesqui e Garcia, precisam ser escolhidos, preparados e consumidos, e, isso de alguma maneira evidência a identidade do grupo, por meio das técnicas empregadas no cultivo e no preparo do alimento, na organização e distribuição. (CANESQUI; GARCIA, 2005, p. 9) Tudo isto se pauta na cultura, que podermos definir ao mesmo tempo como um comportamento humano e uma ação simbólica. Portanto, é uma conduta que, 
embora se situe dentro de um determinado padrão, produz, reproduz, conserva, cria e transmite algo. E as verdadeiras questões a respeito são: qual sua importância? O que significa?

A cultura dá sentido e significado ao mundo, não apenas um, mas vários significados relativos a diferentes contextos. Os mesmos elementos em locais diferentes podem ser apropriados de maneiras distintas, referentes a inúmeras instâncias da vida social. $\mathrm{O}$ indivíduo age de acordo com sua percepção de mundo, ao mesmo tempo subjetiva e coletiva, para efetivar sua ação precisa saber que ela é possível e compreensível dentro de seu grupo. Ou seja, que dentro de seu sistema cultural poderá alcançar seus objetivos, por meio de determinadas ações, e, além disso, interpretar dentro disso as ações dos outros membros de seu grupo. Deste modo, a comida é um elemento que não deve ser visto como separado da rede que o tangencia, se o isolamos como fato cultural, nós tendemos a criar uma interpretação fragmentada e falha. (GEERTZ, 1989, p.8-9)

\begin{abstract}
A comida foi e ainda é um capítulo vital na história do capitalismo. Muito antes dos dias de hoje, o capitalismo procurou por toda parte transformar os antigos desejos por novos meios. As comidas têm histórias sociais, econômicas e simbólicas complexas, diz Sidney Wilfred Mintz (2001), e o gosto do ser humano pelas substâncias não é inato, forjando-se no tempo e entre os interesses econômicos, os poderes políticos, as necessidades nutricionais e os significados culturais. (CANESQUI; GARCIA, 2005, p.)
\end{abstract}

\section{A comida nas comunidades tradicionais}

A comida em comunidades tradicionais remanescentes de quilombo possui características próprias. Pois, estas comunidades vivenciam sua economia de maneira distinta, com pouca ou nenhuma acumulação de capital, exercendo na maioria das vezes a agricultura familiar de subsistência e comercializando apenas o excedente. Sua produção é feita a partir da utilização de recursos naturais, renováveis presentes no ecossistema local.
A Fundação Cultural Palmares, órgão do Ministério da Cultura, até 2013 havia emitido 1.845 certificações atestando que comunidades negras rurais eram remanescentes de quilombos. (BRANDÃO; JORGE, 2013, p. 214)

As comunidades negras rurais que vivenciam disputas pela posse tradicional de seu território. Nem sempre se associaram a ideia clássica de quilombo, como uma forma de resistência da cultura negra à escravidão. Pelo contrário, seus mitos de origem estudados por pesquisadores da história e da antropologia nas décadas de 1970 e 1980, com frequência remontavam à processos de doações senhoriais feitas após a abolição da escravidão no Brasil em 1888. (MATTOS; ABREU, 2013, p. 108)

Porém, é interessante destacar que nas décadas de 1980 e 1990, com o Brasil envolto no processo de redemocratização política após o fim da Ditadura Militar, havia se formado um relativo consenso sobre a estabilidade das desigualdades sociais, bem como, sua relação implícita com a raça. E então, tornara-se relevante desenvolver medidas de enfrentamento a isso, fomentando a discussão de políticas públicas, não só dentro do aparelho estatal, mas também com uma abertura para participação dos movimentos sociais na política nacional. Assim o movimento negro ganhou visibilidade com "a preparação e a realização da Marcha Zumbi dos Palmares contra o Racismo, pela Cidadania e pela Vida, em 1995. " Que gerou um documento com propostas de políticas específicas e ações afirmativas. (JACCOUD, 2008, p. 58-59)

Neste contexto a Constituição Brasileira de 1988 trouxe possibilidades legais para a aplicação de políticas de reparação à escravidão africana no Brasil. As principais eram: a titulação coletiva de terras para comunidades negras rurais reconhecidas como remanescentes de quilombo e a legitimação oficial de patrimônios imateriais "relativos à herança das populações escravizadas". No art. 68 do Ato das Disposições Transitórias o direito de posse era garantido por meio da titulação definitiva emitida pelo Estado. Enquanto nos arts. 215 e 216 a partir de uma noção ampliada de direitos, a proteção legislativa se 
estendia a bens de natureza material e imaterial dos diferentes grupos formadores da sociedade brasileira. (MATTOS; ABREU, 2013, p. 108-109)

O decreto de 3.551, 4 de agosto de 2000, por sua vez, fortaleceu esta perspectiva tornando os bens de natureza imaterial, sob jurisdição do Ministério da Cultura, foco de uma política própria de inventário, referenciamento e valorização. A inserção destes novos patrimônios indicava, segundo Martha Abreu, novas formas de valorizar, comemorar e guardar memórias do passado. Ou seja, a integração de novos grupos sociais que almejavam reconstruir seu passado e seus referenciais identitários, com o apoio do Estado e de especialistas para se tornarem parte da identidade nacional. (ABREU, 2007, p. 353)

De modo geral, estas comunidades procuraram se fixar em locais que permitissem 0 cultivo e a permanência segura, como áreas de florestas, próximas a locais com água potável, em alguns casos junto a montanhas também. Logo, as atividades como a pesca, extrativismo vegetal, caça, agricultura familiar pouco diversificada e a criação de animais de pequeno porte (aves, porcos) são elementos comuns, que se perpetuaram e possibilitaram a permanência e o desenvolvimento dos quilombos. Condições como essas influíram ativamente na definição de seus sistemas alimentares, suas cozinhas, que possuem por um lado a riqueza culinária própria manipulação de alimentos frescos e orgânicos, uso do fogão de lenha e utensílios artesanais. Por outro são limitadas pela pobreza estrutural, que impede o acesso amplo a infraestrutura. (BRANDÃO; JORGE, 2013, p. 214215)

No campo da segurança alimentar e nutricional (SAN), existem ainda poucos estudos para pensar as implicações da pobreza no sistema alimentar quilombola. Em 2006, a Chamada Nutricional Quilombola, uma pesquisa que objetivava fazer um levantamento das características nutricionais em comunidades quilombolas escolhidas nas cinco regiões brasileiras, coletou dados que apontavam para a alta incidência da desnutrição em crianças de 0 a 5 anos, embora isso não fosse uma regra geral.
Outros estudos, mostraram que a quantidade de alimentos consumidos pelas famílias quilombolas muitas vezes é insuficiente. Outra pesquisa em 2008, com as mesmas sessenta comunidades elencadas em 2006, demonstrou que a dieta quilombola era principalmente constituída pelos alimentos cultivados localmente, o que caracterizava o consumo restrito e irregular. (BRANDÃO; JORGE, 2013, p. 218-219)

Por outro lado, essa forma de viver permeada por adversidade, cria os saberes destas comunidades, fruto de seu contato direto e constante com a natureza, evidenciados nas estratégias para sua sobrevivência e nos discursos que dão significados aos seus modos de vida:

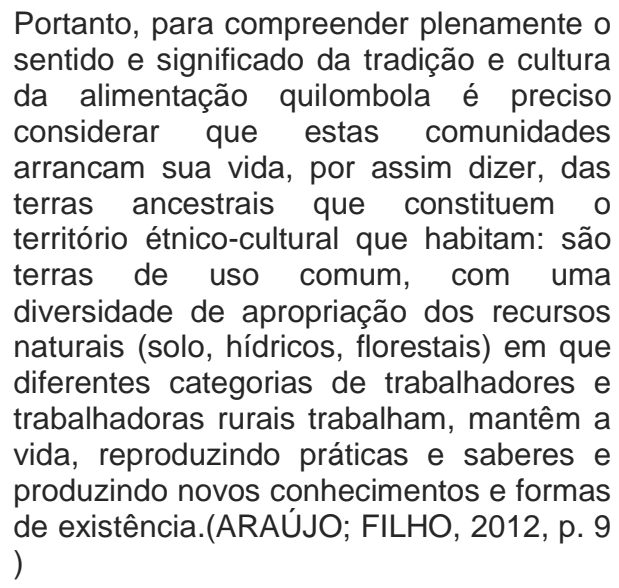

A valorização das cozinhas tradicionais se vincula ao reconhecimento de suas identidades e seus modos de vida. A comida pode ser então, um marcador identitário, que os grupos utilizam como "sinais diacríticos, símbolos de uma identidade reivindicada. " Isso é muito mais do que uma lista de receitas especificas cristalizadas no tempo, mas toda uma maneira de lidar com a comida que muda conforme os grupos alteram sua forma de viver $e$ interagir com o espaço. A cozinha como uma unidade de pertencimento segue caminhos distintos próprios de seu contexto histórico social, com adição e subtração de alimentos e técnicas. Podemos pensar também, a feijoada como uma comida própria para a demarcação identitária, na medida em que, supera a dupla arroz e feijão. 
Esse prato não requer apenas mais alguns ingredientes, uma adição de elementos à dupla feijão-com-arroz. Ele implica uma transformação, tendo virado prato nacional, prato de ocasiões especiais, símbolo de uma identidade reivindicada. Assim, se o feijão com arroz é o comum, do dia-a-dia, a feijoada é especial, podendo ser também apresentada em ocasiões fora do comum, como quando se convida um estrangeiro à mesa, para mostrar um 'pouco do país' (DaMatta, 1987). Em suma, como uma espécie de 'carteira de identidade alimentar brasileira'.

Existem, em outros lugares, pratos semelhantes à feijoada brasileira. No entanto, a diferença está ligada não tanto aos seus ingredientes e ao modo de preparo, mas ao seu significado. Peter Fry (1982), ao observar esse fenômeno, fazuma diferença entre 0 prato no Brasil e nos EUA, onde é soul food, ligado a uma identidade étnica, reivindicada pelo grupo afrodescendente, o que faz com que possa representar, simbolicamente, este grupo inclusive em suas lutas sociais.

A diferença é que, no Brasil, a feijoada, criada na senzala, sofreu um processo de transformação para ocupar esse lugar de destaque, unificador, símbolo de nacionalidade. Assim, foi retirada do grupo original, passando a ser de todos. Esse fato indica um aspecto da dinâmica da sociedade brasileira, na qual itens culturais criados por grupos dominados são apropriados e 'domesticados', perdendo assim a capacidade de simbolizar o grupo original. (MACIEL, 2005, p.52)

O município do Rio de Janeiro com mais de 6 milhões de habitantes destaca-se por seu relevo acidentado, onde se ressaltam 3 grandes maciços que abrigam áreas de conservação ambiental. Isto traz para a cidade um paradoxo, se por um lado é uma cidade que preserva fragmentos da biodiversidade típica da Mata Atlântica, por outro lado o crescimento urbano ameaça tais áreas. Numa destas áreas de preservação localiza-se no Maciço da Pedra Branca, zona oeste da cidade do Rio de Janeiro, território objeto das investigações que instruem este artigo. Esta floresta resguarda descentes dos povos originários e comunidades tradicionais que têm na agricultura a sua maior expressão econômica e cultural.
A região, na década de 1930 a região foi descrita em sua fauna, flora, geografia e atores sociais na obra O Sertão Carioca escrita por Armando Magalhães Corrêa (1936). Área em que estão localizados dois quilombos recém-certificados pela Fundação Cultural Palmares Cafundá Astrogilda (16/08/2014) e Camorim (23/08/14), mas que representam um fragmento de uma comunidade tradicional mais ampla composta por sitiantes em sua maioria ainda sobrevivendo da lavoura.

A Comunidade Cafundá Astrogilda se diz remanescente de quilombo e foi certificada como tal, pela Fundação Cultural Palmares no dia 16 de agosto de 2014, durante uma Cerimônia Pública realizada dentro do PEPB, criando oficialmente com isso o Quilombo Vargem. É o núcleo familiar da matriarca Astrogilda Ferreira da Rosa Mesquita, benzedeira conhecida na região por praticar curas com uso de ervas. Mas, muito antes de serem quilombolas os moradores da área já eram agricultores.

Leonardo Soares dos Santos aponta isso em seu artigo sobre o cotidiano dos agricultores do Sertão Carioca, ou seja, as terras que correspondem às antigas freguesias rurais do Rio de Janeiro: Campo Grande, Guaratiba, Jacarepaguá, Irajá e Santa Cruz. Segundo ele, nessas áreas a ocupação remontava aos engenhos ou fazendas de café dos séculos XVIII e XIX pertencentes, em sua maioria, a ordens religiosas de beneditinos ou carmelitas.

Em algumas áreas, os lotes rurais tinham se originado de arrendamentos, aforamentos ou livres concessões dos proprietários aos seus escravos ou exescravos. Fridman destaca que isso era uma prática comum entre os Beneditinos. Seus escravos possuíam pequenas roças e gado para seu sustento, sendo permitida a comercialização de seu excedente, contanto que não exercessem "ofício para lucro". Em 1871, o Mosteiro de São Bento libertou os 918 escravos que trabalhavam naquelas terras. Há indícios de que alguns deles tenham permanecido morando e trabalhando naquelas terras. (SANTOS, 2011, p. 326)

O autor destaca ainda na nota de rodapé no 9 a existência de famílias da região do Camorim, que se declaravam descendentes de escravos fugitivos. 
(SANTOS, 2011, p. 327) O Quilombo do Camorim possui um processo de articulação anterior ao que ocorreu na Comunidade Cafundá Astrogilda, embora esta tenha sido certificada um pouco antes.

Cáceres aponta em seu artigo sobre a mudança da paisagem do bairro Camorim que não existe homogeneidade no local e sim uma multiplicidade de atores sociais entre os quais se encontram os "ex-escravos do engenho dos beneditinos, os descendentes dos antigos lavradores e pequenos agricultores do outrora 'sertão carioca', os despossuídos do extinto Banco de Crédito Móvel" (CÁCERES, 2014, p. 175) Essa multiplicidade é ainda no caso das duas comunidades acrescida da presença de outros moradores, sejam eles trabalhadores da construção civil que permanecem por períodos limitados, ou moradores de condomínios e casas construídas na área do PEPB (a partir da cota dos $100 \mathrm{~m}$ de altura) ou ao redor.

Nas festas dos quilombos observadas entre 2014 e 2016, comumente a feijoada era eleita como principal comida definindo o eixo organizacional da comemoração. As festas observadas foram a Festa de Certificação da Comunidade Cafundá Astrogilda em 16 de agosto de 2014, as festas da "Consciência Negra" que ocorrem anualmente no dia 20 de novembro e a $1^{\underline{a}}$ Festa de São Jorge do Quilombo do Camorim no dia 23 de abril de 2016.

Embora no cotidiano as pessoas não consumam frequentemente esta comida, nem mesmo nas festas que realizam internamente, a visão de que a feijoada representa a identidade quilombola, faz com que esta comida seja considerada a escolha mais adequada nos momentos em que se decide expor uma identidade comunal para outras pessoas. Por vezes, vi a feijoada ser servida sempre seguindo a receita "tradicional" o feijão cozido com várias partes do porco (orelhas, rabo, pés) servida com laranjas, couve, farofa. Ocupando lugar central nas festividades

Poderíamos então apontar para um ethos retórico próprio de um estereótipo, dimensionado em duas vias o caráter aparente, tal como é apresentado e o próprio discurso que objetiva algo. $O$ ethos, compreende um sistema referencial dentro do qual a retórica enunciada vai se inserir. Sua eficácia reside em que a forma de enunciação, não esteja implícita no enunciado, ou seja, comunica algo pela fala, mas também por outros mecanismos, mas de forma sugestiva e direcional, que depende de um dado sistema referencial que num sentido amplo poderia ser o imaginário e num sentido restrito a própria situação, o ethos. (MAINGUENEAU, 2008, p.57)

Ou seja, nas festas da Consciência Negra realizadas durante as observações participantes, anualmente no dia 20 de novembro no Parque Estadual da Pedra Branca (PEPB - RJ) e nas comemorações da certificação como comunidade remanescente de quilombo na Comunidade Cafundá Astrogilda se formatava o ethos próprio de um quilombo com decoração tribal, comida tradicional, discursos de empoderamento racial, com a defesa da cultura afro-brasileira.

Isso não significa que o ethos seja a realidade menor do evento, mas apenas a realidade de um ponto de vista discursivo, tanto por dados imagéticos quanto por dados verbais ou outros elementos correlatos. Então estas características que são na verdade internas, para o receptor são significadas a partir de referenciais externos, aos quais o locutor de alguma maneira também se reporta, podemos então por fim propor que 0 ethos trata mesmo da construção de uma identidade e a uma série de representações sociais. (MAINGUENEAU, 2008, p. 59-60)

Ou seja, os membros do quilombo construíam um discurso étnico, por meio de diversos signos, mas principalmente a comida, esse discurso era aceito e validado por pessoas que não pertenciam ao grupo, mas participavam das comemorações, nos moldes propostos pelo quilombo, ouvindo as músicas escolhidas, comendo a feijoada, comprando os produtos artesanais expostos. Essas pessoas eram por vezes contatos relacionados ao comércio dos produtos cultivados e visitantes sem uma relação com a comunidade. 


\section{Os saberes como forma de construir uma economia da reciprocidade}

O saber valorizado e presente nos mais diversos âmbitos do trabalho é aquele que não pode ser simplesmente fragmentado, formalizado e aplicado para ensino formal numa instituição, mas sim que tendo sido apreendido empiricamente no cotidiano possibilita ao indivíduo agir, refletir e criar. Seria, portanto, seu discernimento, capacidade de coordenação, gestão, comunicação, na cultura da sociedade. Deste modo, se define por uma potência prática, pelo hábito e interesse em reproduzir este efeito "em novos saberes". Além disso o saber não poderia em princípio ser mercantilizado. (GORZ, 2005, p. 9, 10,32)

André Gorz propõe que o pleno desenvolvimento dessa capacidade intelectual humana seria a forma de riqueza ideal, uma outra economia, que não funcione a partir de uma "pilhagem do bem comum e no desmonte da coletividade" gerando miséria, devia-se, portanto, desvincular valor de prosperidade. O movimento contrário a globalização, se contrapõe a desarticulação da coletividade, à industrialização excessiva dos países subdesenvolvidos que privatizam o saber e consequentemente 0 bem comum. (GORZ, 2005, p. 5-11)

No caso de nichos econômicos específicos que produzem com base nos saberes tradicionais em pequena escala, de modo que, exista uma aproximação entre produtor e consumidor, objetivando além do lucro o desenvolvimento de laços afetivos com seus clientes. Conseguem escapar da lógica dominante do mercado, funcionando sem contar com seus elementos formativos, o sistema econômico burguês, capital, propriedade, trabalho assalariado; Estado, comércio exterior, mercado mundial. (MARX, 2008, p.45)

Funcionam localmente, se estabelece um vínculo ou relação entre agricultora (o) $\square$ agricultora (o) entre agricultora (o) $\square$ consumidor (a) e entre consumidor (a) $\square$ consumidor (a). Não se trata apenas de uma compra mercantil propiciada pelo ambiente refrigerado dos supermercados ou shoppings que povoam a região. Consumidoras e consumidores escolhem o calor da praça, o encontro, o abraço, a troca de amabilidades. Existe um valor moral ali. Há uma escolha. "Do ponto de vista antropológico, o princípio de reciprocidade corresponde, portanto, a um ato reflexivo entre sujeitos, a uma relação intersubjetiva e não apenas a uma simples permuta de bens ou de objetos, como é a troca" (SABOURIN, 2010, p.4).

\section{0 exemplo das feiras}

A partir da movimentação promovida pelas redes de agroecologia, temos a oportunidade de verificar em pleno século XXI, em uma capital global as regras básicas para economia primitiva. Há evidências de que a agricultura outrora invisibilizada e decadente está encontrando na solidariedade, os motivos para produzir mais alimentos e produtos diversos. Observamos A Feira Orgânica de Jacarepaguá e a Feira da Roça de Vargem Grande. Embora as feiras não sejam inteiramente formadas por produtores quilombolas, são espaços em que possuem relações que permitem a comercialização de seus produtos.

A feira acaba sendo para os produtores um espaço de formatação de memória coletiva e fortalecimento do grupo. Não apenas porque os produtores conversam entre si. Durante um período determinado trabalham ajudando uns aos outros como também porque entram em contato com os consumidores engendrando fora do grupo uma nova rede de relações. No trabalho de campo na Feira de Jacarepaguá muitas vezes, ao questionar a produtora orgânica Juliana Diniz em nossas primeiras visitas percebemos o uso de "nós" em suas colocações e não do "eu", como se poderia esperar. Constantemente ela se colocava como parte de um grupo.

A proximidade entre produtores e consumidores na feira propicia uma série de trocas, muitas vezes sobre o conhecimento tradicional 
materialmente representado pelo produto. Nas feiras orgânicas e agroecológicas que surgem por toda a cidade do Rio de Janeiro e sua região metropolitana se constitui uma territorialidade emergente. Através da participação dos agricultores aprendemos que a feira é muito mais que um mercado. Esse vínculo mostrou que valorizam um mercado onde podem expressar sua cultura oral, sua dádiva, seu conhecimento. Aqui entendemos a feira como lugar de construção do conhecimento, como lugar de comunicação e trocas simbólicas. Compreendemos que ao agregar valor e dar qualidade aos produtos e novidades insere-se no princípio da dádiva. "De fato, cria-se uma territorialidade de reciprocidade em torno de um produto específico" (SABOURIN, 2008, p.14).

Os consumidores das feiras são adultos, em sua maioria mulheres, em busca de alimentos saudáveis e outros produtos comercializados. A Feira de Jacarepaguá no Largo de Jacarepaguá, no período que acompanhamos não oferecia alimentos preparados para consumo na feira, apenas frutas verduras hortaliças, mudas e ervas medicinais. Enquanto na Feira da Roça no Largo de Vargem Grande, comercializava frutas, verduras, artesanato e oferecia algumas opções para este tipo de consumo, como sucos naturais, sanduiches e doces caseiros.

Quando consumidor oferece a atenção, o olhar, a pergunta e se põe no lugar de quem ignora informação sobre o alimento comercializado, forma-se essa relação onde o agricultor exerce a dádiva do seu conhecimento que não está ligado a mercantilização. Ele doa seu conhecimento ao doar a sua palavra. Vivenciamos na Feira Agroecológica da Freguesia um momento que demonstrou isso. Uma consumidora pergunta por capim limão, erva para um chá bastante apreciado no mercado. Na banca há uma planta parecida, o agricultor Washington Adam, cujo apelido é Gaúcho, informa a senhora que se trata de citronela e não capim limão. Conversam sobre a citronela e suas propriedades repelentes.

A senhora não compra a planta fresca. Em contrapartida encomenda uma porção de repelente para animais domésticos que Gaúcho vende a $\mathrm{R} \$$ 5,00 (cinco reais). E ao entregar o produto adquirido afirma: "Depois eu te ensino a fazer". Ou seja, comercializa e ao mesmo tempo socializa a fórmula do repelente veterinário. Identificamos esse fato com a reciprocidade na economia e no cuidado. A lógica mercantil não é ceder fórmulas e receitas, mas escondê-la na busca do lucro.

Outra experiência registrada durante as feiras vem da inauguração da Feira da Roça de Vargem Grande, onde uma de suas principais lideranças, o agricultor e quilombola Jorge Cardia Valois afirma que muito melhor que vender é ver a comunidade reunida naquele dia e local. A moeda não é o valor fundamental para o agricultor tradicional. A troca de gentilezas, a presença, o compartilhar é o valor preponderante no estabelecimento das festividades e feiras.

O agricultor-feirante oferece a dádiva do produto local, qualificado, sem agrotóxicos, com certificação orgânica, tendente a ser qualificado como carbono zero por ser produzido muito próximo ao mercado consumidor. A rede de parentela se alterna do papel de produtores agrícolas e de consumidores. A vizinhança e outros membros da comunidade exercem apenas o papel de consumidores. Há um contexto de escolha do alimento orgânico, e uma valoração da agricultura urbana. Há, portanto um imperativo ético no estabelecimento destes mercados locais.

A comercialização dos produtos como doces caseiros permite nesse transito de ideias, além do acumulo de renda, a visibilização parte da cozinha quilombola, por meio da exposição e comercialização dos produtos. Os doces do Quilombo Cafundá Astrogilda veem com um adesivo no pote com o símbolo da comunidade.

\section{Considerações Finais}

O artigo de Andreas Huyssen (2000) que descreve como a sociedade está mudando de foco, deixando o "privilégio dado ao futuro que tanto caracterizou as primeiras décadas de modernidade do século XX" (HUYSSEN, 2000, p. 9). Na mesma medida que abandona o mito do futuro há uma ênfase 
memorialista que o autor denomina "passados presentes". "A partir da década de 1980 o foco parece ter se deslocado dos futuros presentes para os passados presentes" (HUYSSEN, 2000, p. 9). Notamos, portanto, que o olhar para o passado em busca de respostas para interpretar um futuro confuso e inseguro, em alguma, explica a atualidade de propostas antigas e mesmo a aplicabilidade de suas conclusões.

E, continua o autor:

De fato, questões de temporalidades diferentes e modernidades em estágios distintos emergiram como peças-chaves para um novo entendimento rigoroso dos processos de globalização a longo prazo que procurem ser algo mais do que apenas uma atualização dos paradigmas ocidentais de modernização. (HUYSSEN, 2000, p.10)

Vemos a necessidade de pactuar coletivamente um vocabulário que contemple a possibilidade de aproximar a dádiva no campo da economia solidária ou do comércio justo. Há uma proliferação de expressões que acabam por designar uma economia contra hegemônica, fundada numa ética de solidariedade. Podemos descrever: economia solidária, economia popular, mercados curtos, compras coletivas, comércio justo. Do ponto de vista da comunidade tradicional o vocabulário para designar este é ainda mais vasto e difuso.

No entanto, a comercialização em pequenos mercados locais parece sintetizar bem todo este anseio por um mercado socialmente construído e que se baseie na sociabilidade, na horizontalidade de saberes e na proximidade. Pode com base nestes pressupostos, se unir aos saberes e valores tradicionais como forma de criação de nichos, em que a economia se desenvolve de forma diferenciada. Que dialoga constantemente com os consumidores e cria uma relação de reciprocidade que envolve produto, conhecimento, afetividade, representatividade. Não se trata de uma solução, e sim de um caminho que pode ser acessado pelas comunidades para visibilizar e valorizar suas cozinhas e conhecimentos, que a margem do grande mercado recria noções de reciprocidade.

\section{Referências}

ABREU, Martha. Cultura Imaterial e patrimônio histórico nacional. In: ABREU, Martha; SOIHET, Rachel; GONTIJO, Rebeca. Cultura política e leituras do passado: historiografia e ensino de História. Rio de Janeiro: Civilização Brasileira, 2007. p. 351-370.

ARAÚJO, Maria S. G. de; FILHO Domingos L.L. Cultura, trabalho e alimentação em comunidades negras e quilombolas do Paraná. In: I SEMINÁRIO SOBRE ALIMENTOS E MANIFESTAÇÕES CULTURAIS TRADICIONAIS, gt.4, 2012, São Cristóvão (SE). Anais do I Seminário Sobre Alimentos e Manifestações Culturais Tradicionais. Disponível em: <http://www.grupam.net/anais-do-i-seminariosobre-alimentos-manifesta\%C3\%A7\%C3\%B5 esculturais-tradicionais/>. Acesso em: 01 mar. 2016.

BRANDÃO, André; JORGE, Amanda L. Comunidades quilombolas, Acesso a programas Sociais e Segurança Alimentar e Nutricional. In: ROCHA, Cecília et al. (org.). Segurança Alimentar e Nutricional: perspectivas, aprendizados e desafios para as políticas públicas. Rio de Janeiro: Editora Fio Cruz, 2013. p. 213-225.

CÁCERES, Luz Stella R. Transformações da Paisagem e a memória do Camorim. Revista Antíteses, Londrina, v.7, no 14, p.171-198, jul./dez. $2014 . \quad$ Disponível em:< https://www.researchgate.net/publication/272641491 Transformacoes da Paisagem_e_a Memoria_em_C amorim>. Acesso em: Acesso em: 01 de mar. 2016.

CANESQUI, Ana Maria; GARCIA, Rosa W. D (org.). Uma Introdução à Reflexão sobre a Abordagem Sociocultural da Alimentação. In: Antropologia e Nutrição: um diálogo possível. Rio de Janeiro: Editora FIOCRUZ, 2005. (Coleção Antropologia e Saúde) p.922.

CORRÊA, Armando Magalhães. O sertão carioca. Rio de Janeiro: Imprensa Nacional, 1936.

GEERTZ, Clifford. A interpretação das culturas. Rio de Janeiro: Editora LTC, 1989.

GORZ, André. O imaterial: conhecimento, valor e capital. Traduzido por: Celso de Azzan Junior. São Paulo: Annablume, 2005.

HUYSSEN, Andréas. Seduzidos pela memória. Rio de Janeiro: Aeroplano, 2000.

JACCOUD, Luciana. Capítulo 2 - Racismo e república: o debate sobre o branqueamento e a discriminação racial no Brasil. In: THEODORO, Mário (org.). As políticas públicas e a desigualdade racial no Brasil 120 anos após a abolição. Brasília: Ipea, 2008. Disponível em: < http://www.mpgo.mp.br/portalweb/hp/41/docs/desigual dades raciais .pdf>. Acesso em: 20 de jun. de 2015. LAPLANTINE, F.; TRINDADE, L. O que é imaginário. Editora Brasiliense: Brasília: Editora Brasiliense, 
1996.

Disponível

em: <https://www.passeidireto.com/arquivo/4256 581/oque-e-imaginario---laplantine-francois-et-trindadeliana---pdf>. Acesso em: 14 ago. 2014.

MACIEL, Maria Eunice. CULTURA E ALIMENTAÇÃO OU O QUE TEMM A VER OS MACAQUINHOS DE KOSHIMA COM BRILLAT-SAVARIN? Horizontes

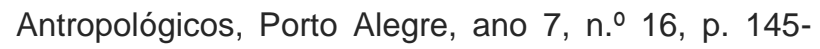
156, 2001. Disponível em: < http://www.scielo.br/pdf/ha /v7n16/v7n16a08.pdf>. Acesso em: 01 de mar. 2016.

MACIEL, Maria Eunice. Identidade Cultural e Alimentação. In: Antropologia e Nutrição: um diálogo possível. Rio de Janeiro: Editora FIOCRUZ, 2005. (Coleção Antropologia e Saúde)

MARX, Karl. Contribuição à Crítica da Economia Política. Traduzido por: Florestan Fernandes. 2. ed. São Paulo: Expressão Popular, 2008.

POSSETI, Sírio; SOUZA-E-SILVA, Maria C. (org.). MAINGUENEAU, Dominique. Cenas da enunciação. Traduzido por: Maria Cecilia Pérez de Souza-e-Silva, et al. São Paulo: Parábola, 2008.

MATTOS, Hebe; ABREU, Martha (orgs.). Lugares do tráfico, lugares de memória: novos quilombos, patrimônio cultural e direito a reparação. In: MATTOS, Hebe (orgs.). DIÁSPORA NEGRA E LUGARES DE MEMÓRIA: A história oculta das propriedades para o tráfico clandestino de escravos no Brasil imperial. Niterói: Editora da UFF, 2013.

SABOURIN, Eric. Reciprocidade e análise de políticas públicas rurais no brasil. Revista Ruris. Campinas, v. 6, no 2, 2012. Disponível em:< http://www.ifch.unicamp.br/ojs/index

.php/ruris/article/view/1538/1046>. Acesso em: 05 de set. 2013.

SABOURIN, Eric. Economia solidária no meio rural brasileiro: uma analise a partir da noção de reciprocidade. Rio de Janeiro, 2008. Disponível em: <http://www.facesdo

brasil.org.br/midiateca/cat_view/927-economia-

solidaria/956-artigos-documentos-e-relatorios

.html?start=20>. Acesso em: 18 de dez. 2012.

SABOURIN, Eric. Políticas públicas de desenvolvimento rural e reciprocidade. Anais do $4^{\circ}$ Encontro da Rede de Estudos Rurais. Curitiba, 2010. Disponível em: <http://www.redesrura is.org.br/sites/default/files/Pol\%C3\%ADticas\%20p\%C 3\%BAblicas\%20de\%20desenvolvimento\%20rural\%20 e\%20reciprocidade.pdf $>$. Acesso em: 18 de dez. 2012.

SANTOS, Leonardo S. Onde se trabalha, também se bebe e se conversa: o cotidiano dos pequenos lavradores do sertão carioca. Revista de História Regional, Ponta Grossa, v.16, nº 2, jul. / set., 2011. p. 323-350. Disponível http://revistas2.uepg.br/index.php/rhr /article/view/2419/2494>. Acesso em: 12 nov. 2015.
SIMMEL, Georg. Sociologia da refeição. Traduzido por: Edgard Malagodi. Revista Estudos Históricos, Rio de Janeiro, v. 1, ํㅜ 33, p. 159-166, 2004. Disponível em: http://bibliotecadigital.fgv.br/ojs/index.php/reh/article/vi ew/2218/1357>. Acesso em: 01 de mar. 2016. 